\title{
Psychological Resources and Strategies to Cope with Stress at Work
}

\author{
Recursos psicológicos y estrategias de afrontamiento con estrés en el trabajo \\ Edna Rabenu ${ }^{1 *}$ and Eyal Yaniv²
}

\begin{abstract}
Introduction: the choice of strategies to cope with stress has differential effects on individual and organizational outcomes (e.g. well-being and performance at work). This study examined to what extent individuals differing in their positive psychological resources (optimism, hope, self-efficacy and resilience) implement different strategies to cope with stress in terms of change, acceptance, or withdrawal from a source of stress in an organizational setting.

Method: A questionnaire was filled out by 554 employees from different organizations representing a wide range of jobs and positions.

Results: Structural Equation Modeling $\left(\mathrm{SEM} ; \chi^{2}(7)=27.64, p<.01, \mathrm{GFI}=.99, \mathrm{NFI}=.91, \mathrm{CFI}=.93\right.$, RMSEA $=.07$ )

Conclusion: the results indicated that psychological resources (optimism, hope, self-efficacy and resilience) were positively related to coping by change and by acceptance and negatively related to withdrawal. The theoretical implications are discussed.

\section{Resumen}

Introducción: la elección de estrategias de afrontamiento al estrés, tiene efectos diferenciales en los resultados individuales y organizacionales (por ejemplo, el bienestar y el rendimiento en el trabajo). En este estudio se examinó hasta qué punto las personas que difieren en sus recursos psicológicos positivos (optimismo, esperanza, autoeficacia y resiliencia) implementan diferentes estrategias para hacer frente al estrés en términos de cambio, aceptación o retirada de una fuente de estrés en un entorno organizacional

Método: 554 empleados de diferentes organizaciones que representan una amplia gama de puestos de trabajo y puestos respondieron un cuestionario.

Resultados: modelado de ecuaciones estructurales $\left(\mathrm{SEM} ; \chi^{2}(7)=27.64, p<.01, \mathrm{GFI}=.99, \mathrm{NFI}=.91\right.$, $\mathrm{CFI}=.93$, RMSEA $=.07$ )

Conclusión: Los resultados indicaron que los recursos psicológicos (optimismo, esperanza, autoeficacia y resiliencia) estaban relacionados positivamente con el afrontamiento por el cambio y por la aceptación, y negativamente relacionados con la retirada. Las implicaciones teóricas son discutidas.
\end{abstract}

\section{Keywords}

Psychological resources; coping; self-efficacy; hope; optimism; resilience.

\section{Palabras Clave}

Recursos psicológicos; afrontamiento; autoeficacia; esperanza; optimismo; resiliencia.

${ }^{1}$ School of Behavioral Sciences, Netanya Academic College, Netanya, Israel.

${ }^{2}$ School of Business administration, Bar-llan University, Ramat-Gan, Israel.

*Corresponding author: edna.rabenu@gmail.com

Manuscript received 13-10-2016; revised 04-04-2017; accepted 05-07-2017.

\section{Introduction}

The perception of stress and the ability to cope with it are very much determined by an individual's personal characteristics (e.g. Pal \& Bhardwaj, 2016). However, what differentiates people in the ways they cope with stress remains unclear. In the current research we hypothesize that optimism, hope, selfefficacy and resilience, psychological resources that make up positive psychological capital (PsyCap), are related to specific 
coping strategies. In particular, the relationship between hope and resilience with coping strategies is explored to help resolve the conceptual ambiguity between these variables and extend the limited research on these relationships in the workplace.

\subsubsection{Strategies for coping with stress}

Coping strategies are basic categories used to classify how people actually react to stress. The best known classification (Lazarus \& Folkman, 1984) identified two major processoriented functions of coping strategies: problem-focused coping and emotion-focused coping. In the former, the individual gathers information about what to do and takes steps to change the reality of the troubled person-environment relationship. The latter function is aimed at regulating the emotions associated with the stress situation. This can involve avoiding thinking about the threat or reappraising it, without changing the realities of the stressful situation (Lazarus, 1999).

This classification of coping provided a broad practical framework for research and practice. Since then, many other classifications have emerged. These differ in terms of the number and range of coping categories (see Skinner, Edge, Altman, \& Sherwood, 2003).

In this study, coping was broken down into three strategies (Clarify this reference). Change corresponds to problemfocused coping as in Lazarus and Folkman (1984) which is aimed at managing stressors. In change coping strategy, the individual actively seeks to solve the problem created by stress. Acceptance is included in emotion-focused coping (Lazarus \& Folkman, 1984). The individual accepts the stressor as a fact that cannot be changed and decides to adapt and adjust (his thoughts and feelings) to the stressful situation. Acceptance can also be theoretically classified as meaning-focused (Folkman \& Moskowitz, 2007). In this case people use their beliefs, values, and goals to find or remind themselves of the benefits of experiencing stress as a way of supporting coping. Withdrawal is also based on Lazarus and Folkman (1984) emotion-focused coping. The individual feels "trapped" in a stressful environment without being able (subjectively) to change it. Therefore, the individual withdraws physically and/or psychologically from the stressful work environment. For further explanation of the reasons for the distribution into three strategies (see Rabenu, Elizur, \& Yaniv, 2015).

\subsection{Positive psychological capital (PsyCap)}

PsyCap is a multifaceted construct which includes beliefs about the self (self-efficacy) and personal resources including resilience, hope, and optimism. Specifically, PsyCap is the individual's positive psychological state characterized by having the confidence (self-efficacy) to take on challenging tasks and invest the effort needed to succeed in them. This includes, making positive attributions (optimism) about succeeding, persevering toward goals in order to succeed (hope) and persevering in the face of problems or difficulties, to transcend them (resilience) (Luthans, Youssef-Morgan, \& Avolio, 2015).
PsyCap is an evidence-based construct (Luthans \& YoussefMorgan, 2017). In the organizational context, PsyCap has been shown to be positively related to job satisfaction, job engagement, well-being, mental health and employee performance and negatively related to stress, turnover intentions, substance abuse and counterproductive workplace behaviors (Avey, Reichard, Luthans, \& Mhatre, 2011; Aybas \& Acar, 2017; Krasikova, Lester, \& Harms, 2015; Rabenu, Yaniv, \& Elizur, 2016). For a review, (see Newman, Ucbasaran, Zhu, \& Hirst, 2014)

\subsection{Coping with Stress and psychological capital (PsyCap)}

Three kinds of personal variables are especially important in shaping stress appraisals (and hence coping): goals, beliefs about the self and the world, and finally the individual's personal resources can be tapped in interactions with the environment (Lazarus, 1999). Lazarus and Folkman (1984) argued that the ways people cope depend heavily on the resources available to them. The pooling of resources enables the coping process (Westman, 2004).

The effort motif is central to both PsyCap (Avey et al., 2011) and coping (Lazarus \& Folkman, 1984). However, in PsyCap, which is considered a resource, effort is general and not focused on a specific situation. Conversely, in coping, effort is specific to the stressful situation. Support for this idea can be found in COR theory (Hobfoll, 1989). According to this theory, even when not experiencing stress, people are motivated to obtain, retain and protect their resource reservoirs. Westman (2004) found that each coping blend is based on both acquiring new resources and preventing the loss of resources. This further supports the idea that PsyCap precedes coping because general motivation is translated into specific efforts to cope with the stress. It goes without saying that there is a feedback cycle between resources and coping. A pool of resources enables the coping process while the later affect the content and quantity of the pool of resources (Westman, 2004).

\subsection{Coping with stress and the psychological re- sources that make up positive psychological cap- ital (PsyCap)}

\subsubsection{PsyCap self-efficacy}

PsyCap efficacy is defined as the individual's confidence in his or her abilities to summon the cognitive resources, motivation, and actions needed to succeed in a task (Luthans et al., 2015). Self-efficacious people set high goals for themselves, welcome and thrive on challenges and persevere in the face of obstacles (Luthans et al., 2015).

Self-efficacy has been shown in the literature to be particularly important as a coping resource (Holahan, Moos, \& Schaefer, 1996). A longitudinal study exploring coping strategies of workers during a merger found that self-efficacy positively predicted the use of problem-focused coping but did not predict coping by avoidance (Amiot, Terry, Jimmieson, \& Callan, 2006). 
Accordingly, we hypothesized:

H1 - Self-efficacy will be positively related to coping by changing the source of stress.

\subsubsection{PsyCap optimism}

Optimists attribute positive events to personal, permanent, and pervasive causes, and negative events to external, temporary, and specific factors. On the other hand, pessimists attribute positive events to external, temporary, and specific attributes and negative events to personal, permanent, and pervasive causes (Seligman, 1998). Thus, optimists are positive and confident about their future even when confronted with negative events while pessimists tend to blame themselves for the negative aspects of their lives, and suppress their own growth opportunities (Luthans et al., 2015).

Optimism has been shown to be an especially important resource for coping (Holahan et al., 1996, p.31). Optimism has been associated with greater use of problem-focused coping strategies (especially when the situation is within their control), and less use of emotion-focused strategies (e.g. EpsteinMathias, 2003; Luthans et al., 2015). Optimists are less likely to cope by withdrawal (disengagement, avoidance, etc.; see for example Carver \& Connor-Smith, 2010).

Optimists attribute negative events (such as chronic stress at work) to external, temporary, and specific factors (Seligman, 1998) and they continue to look favorably and confidently toward the future (Luthans et al., 2015). Accordingly, optimism is positively associated with vigor and dedication (Wang, Liu, Zou, Hao, \& Wu, 2017). In contrast, pessimists tend to more passive reactions such as denial, escape, fatalism or cognitive avoidance (Luthans et al., 2015). This led to the following hypothesis:

H2 - Optimism will be negatively related to coping by withdrawal from the source of stress.

\subsubsection{PsyCap hope}

? defined hope as "a positive motivational state that is based on an interactively derived sense of successful (1) agency (goal-directed energy) and (2) pathways (planning to meet goals)" (p. 287). Accordingly, hope is a cognitive state in which an individual sets challenging (but realistic) goals, and then strives for them with determination and energy (Luthans et al., 2015).

Hope appears in the literature as a coping strategy or as a resource for coping. Korner (1970) referred to hope as a tool for emotional coping with distress, similar to mechanisms of defense. Similary, Lazarus (1999) described hope as an aspect of emotional coping strategy, but also as a state of mind. Many see hope as a personal characteristic or resource that affects the way the individual's copes (e.g. ?). The perception of hope as a resource has become more dominant, especially in light of the transition from a more emotion based to a more cognitively based definition. Here, hope is defined within the cognitive definition of PsyCap.

The connection between hope and stress in the workplace has received little if any attention in research, but there is com- pelling evidence from hope research in other contexts (e.g., clinical and sports psychology) which suggests that hope may be a positive resource in stressful situations (Avey, Luthans, \& Jensen, 2009). Hope may have an impact on individual coping with stress by increasing the motivation to cope with a given situation. It may also operate and through cognitive change by causing an appraisal of the situation as less threatening (Lazarus \& Cohen-Charash, 2001). Individuals high in hope can produce alternatives for achieving their goals when the original ways are blocked (Snyder, Rand, \& Sigmon, 2002). Their willpower and persistence motivate the search for new ways (Snyder, 2002). Therefore, high hope individuals in stressful situations have the ability to find alternatives for action that arouse their energy and engender a sense of control rather than helplessness. Their willpower to achieve their goals in the face of obstacles/challenges leads them to cope successfully with various difficulties including stress due to changing circumstances and/or adapting to stressful situations. Behavioral or psychological withdrawal from work is not consistent with goal achievement but rather with helplessness, which does not characterize those high on hope. We thus hypothesized that among individuals in stressful situations, being high on hope, should decrease withdrawal from the workplace.

H3 - Hope will be negatively related to coping by withdrawal from the source of stress.

\subsubsection{PsyCap resilience}

Resilience is a dynamic process of positive adjustment or adaptation to adversity (Luthans, Vogelgesang, \& Lester, 2006). Resilience also refers to the ability to return to the previous level of functioning (Carver, 1998) and not just "survive" but even thrive in a changing environment, (Luthans et al., 2015). According to Hobfoll (2011), resilience refers to people's ability to withstand the most negative consequences of stressful challenges and remain vigorous, committed and engaged in important life tasks. In other words, resilience is a resource (an ability or potential) that allows individuals to withstand or recover from major stress (Hobfoll, 2011).

Although coping and resilience have been explored as separate areas, coping can be confused with resilience since there is no general agreement about the concept of resilience (e.g. Rabenu et al., 2016). Therefore, we would like to clarify the differences between the two concepts (coping and PsyCap Resilience) before sharing our hypotheses. First, resilience is frequently defined as obtaining good results following exposure to adversity (e.g. Carver, 1998). Also, researchers emphasize subsequent growth (e.g. Luthans et al., 2015). However, coping is defined independently of its outcomes. That is, coping refers to efforts made to manage demands, regardless of their subsequent success (Folkman, 1984).

Second, according to Luthans et al. (2015) "PsyCap resilience is not just a minimal coping or neutralizing agent for difficult times" (p.155). In other words, resilience is an extensive process and not specific and short term as coping.

Luthans et al. (2015) simulated the risk to vaccination 
Figure 1. The relationship between psychological resources (self-efficacy, hope, optimism, and resilience) and coping strategies (change, acceptance, and withdrawal).

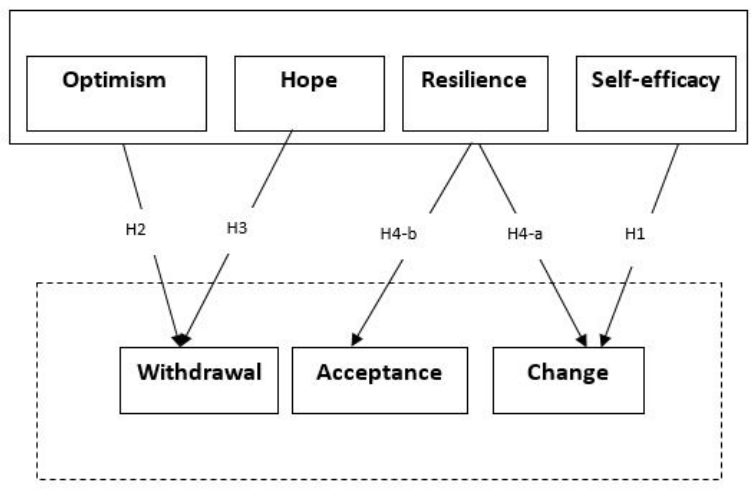

and speculated that approach-coping techniques would be more positively associated with resilience, whereas avoidancecoping techniques would be associated with a negative impact on resilience (see also Holahan et al., 1996).

In order to thrive, people need to cope, at least partially, with the problem itself (coping by change). High-resilience individuals experience more positive emotions and less negative ones (Smith, Tooley, Christopher, \& Kay, 2010), so they can effectively engage in problem-focused coping (Folkman, 1984). However, it requires significant internal work to emerge reinforced from moments of crisis. It has been suggested that a great deal of coping is done through the self: accepting the source of stress and adjusting to the demands. We would like to emphasize here the definitions of resilience as positive adjustment and adaption to adversity (e.g. Luthans et al., 2006, 2015; Masten \& Wright, 2010). The high resilience individual's use of positive emotions as a strategy for coping with stress over time may make it automated, thus requiring minimal attention or cognitive effort, which is extremely beneficial in coping (?). If so, there should be a relationship between resilience and coping through change, and an even stronger relationship between resilience and coping through acceptance. Moreover, as an individual's coping ability shows wider range and variety (that is coping repertoire- the total number of different coping strategies used by the individual) it should give the individual more protection (Epstein-Mathias, 2003). Since resilience refers to the ability to recover and thrive, not just "survive", it should increase the use of both change and acceptance. Thus, we hypothesized:

H4a - Resilience will be positively related to coping by changing the source of stress.

H4b - Resilience will be positively related to coping by accepting the source of stress.

Figure 1 depicts the model and its hypotheses.

\section{Method}

\subsubsection{Sample and procedure}

The sample was made up of 554 employees in organizations in Israel, representing a wide range of jobs; $51 \%$ female and $49 \%$ male. Ages ranged from 18 to $67(M=37.8, S D=9.57)$. Duration of employment in the organization was between two weeks and 45 years (average $=8.18, S D=8.08$ ), and in their current job between two weeks and 35 years $(M=4.46, S D=$ 5.07). Of the respondents, $44 \%$ worked in the hi-tech industry, $13 \%$ in traditional industries, $31 \%$ in services, and $12 \%$ in other industries; $20 \%$ were employed in public institutions, $73 \%$ in private organizations, and $7 \%$ in other settings (NGOs, etc.). Forty-four percent held various levels of managerial positions, and $56 \%$ were not managers.

The participants were sampled in three ways: 100 hardcopy questionnaires were filled out by Business Management or Behavioral Sciences graduate students at Netanya Academic College (delivered by the researcher); 459 questionnaires were distributed by a "snowball" method convenience sample, of which 367 were filled out electronically by means of a designated online questionnaire. The remaining 92 questionnaires were distributed by hardcopy. Five questionnaires were not fully completed, and were excluded from the sample.

\subsubsection{Measures}

\subsubsection{Coping Questionnaire - Special methodology}

Rabenu et al. (2015) pointed to the need to create a new coping questionnaire in response to criticism of the ways in which coping items in validated questionnaires were derived (from theory or somewhat arbitrarily) and worded (Dewe, O'Driscoll, \& Cooper, 2010). In addition, statistical analyses of coping strategies can be improper. For most researchers, factor analysis is the preferred tool to create coping components. Nevertheless, researchers over the years have raised a number of concerns about the data-reduction features of this technique, especially whether using factor loadings as a method for including or excluding coping items reduces the comprehensiveness of the measures (see Dewe et al., 2010). Therefore, we wrote a structured self-report questionnaire to assess ways of coping with stress. The questionnaire was constructed based on Facet Theory (Elizur, 1984). A facet is "a classification of item domains of a given content universe according to some rule" (p.380).

Based on the literature, we differentiated two basic independent facets to define the coping with stress domain: A modalities of coping (including the cognitive, emotional and instrumental coping elements), and B - direction of coping (including the change, acceptance and withdrawal elements). Sample items are: During stressful situations at work I: "Reevaluate the situation as positive", and I: "Look for another job". Items were answered on a 6 point Likert-type scale $(1=$ Very infrequently; 6 = Very frequently).

The empirical results from a Similarity Structure Analysis (SSA) (Elizur, 1984) supported the construct as highly valid (Rabenu et al., 2015). An exploratory Factor Analysis 
yielded three factors (eigenvalue $>1$ ) that explained $57.82 \%$ of the variance, and represented the elements "withdrawal", "change", and "accept" the source of stress. The Cronbach's alpha was .65 (10 items). The Cronbach's alphas for the elements were: change (3 items) $\alpha=.71$, accept (3 items) $\alpha=.53$ and withdrawal (4 items) $\alpha=.76$.

It is difficult to achieve high item reliability because the items express various modalities (Facet A) and partially contradictory coping directions (Facet B), although all of them examine coping as a whole. Guttman (1946) showed that low reliability is to be expected under certain conditions, for instance as a function of the type of data.

2.0.4 Psychological Capital (PsyCap) Questionnaire (PCQ) PsyCap was measured with twenty-four items (Luthans et al., 2015) to test self-efficacy, optimism, hope, and resilience. Each of the four components of PsyCap was measured by 6 items. The resulting score represents an individual's level of positive PsyCap. We translated the PCQ and had it back translated into English by an independent specialist. The back translation was reviewed by Prof. Luthans to assure that the PCQ items were translated properly. Sample items are: "I feel confident presenting information to a group of colleagues" (efficacy), "I feel there are lots of ways around any problem" (hope), "I usually manage difficulties one way or another at work" (resilience), "I always look on the bright side of things regarding my job" (optimism). Items were answered on a 6-point Likert-type scale ( 1 = Strongly Disagree; 6 = Strongly Agree).

The reliability of the original PCQ questionnaire was $\alpha=0.90$. However, the results for optimism $(\alpha=.59)$ and resilience ( $\alpha=.74$ ) were lower than the ones reported by the developers of the questionnaire. Further examination found that one question reduced the reliability of the resilience variable, and three questions reduced the reliability of optimism. All were subsequently removed. The Cronbach's alpha then became .92 .

\subsubsection{Background Questionnaire}

Demographic variables (age, gender, family status, number of children, and level of education) as well as organizational variables (seniority in the organization, seniority in the current job, employment setting, industry, management, and team work) were examined.

\section{Results}

Table 1 presents the mean scores, standard deviations, and inter-correlations of the study variables as well their reliabilities.

Coping by change showed a correlation with coping by acceptance. In other words, change and acceptance tended to be aligned, and the higher the coping by change, the higher the coping by acceptance. On the other hand, there was no significant correlation between coping by withdrawal and the other modes of coping.
Figure 2. The relationship between psychological resources (self-efficacy, optimism, hope, and resilience) and coping strategies (in terms of change, acceptance, or withdrawal).

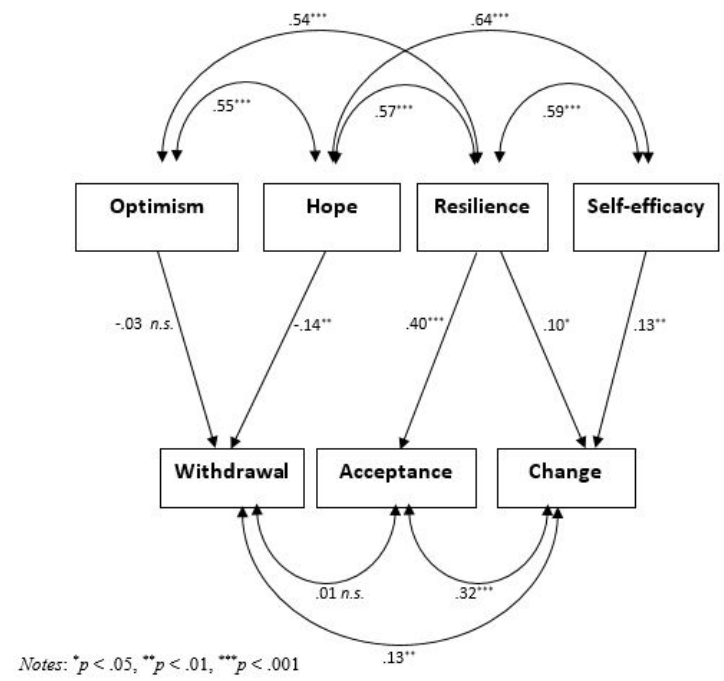

PsyCap capacities were correlated weakly with coping by change, more strongly with coping by acceptance, and negatively with coping by withdrawal

\subsubsection{Structural Equation Modeling}

We performed Structural Equation Modeling (SEM) with AMOS version 7 to examine the hypotheses. SEM analysis examines the degree to which the proposed model fits the research data, and examines the model as a whole. The results are presented according to McDonald and Ho (2002).

Figure 2 depicts the model as a whole. Several measures of approximation were employed. In the Normed Fit Index (NFI), the Goodness-of-Fit Index (GFI), and the Comparative Fit Index (CFI) a degree of fit above 0.90 is considered sufficient (McDonald \& Ho, 2002). The approximation measures found here were above 0.90 , and therefore met the approximation criteria $(\mathrm{GFI}=.99, \mathrm{NFI}=.91, \mathrm{CFI}=.93)$. In addition, lackof-fit was measured by the RMSEA (root mean square error of approximation), where the value of a suitable fit should be lower than 0.1 (Jöreskog \& Sörbom, 1989). In the current study, the results for lack-of-fit were sufficient (RMSEA = .07). It is recommended that $\chi^{2} / \mathrm{df}$ be less than 2 ; this was not the case in this study A $\chi^{2}$ test to examine the difference between the model and the data found the $\chi^{2}$ to be significant; i.e., a statistical difference between the proposed model (SEM) and the resulting data of: $\chi^{2}(7)=27.64, p<.01$ (McDonald $\&$ Ho, 2002). The percentage of variance of the endogenous variables explained by the model was reasonable, between $2.4 \%$ and $16.1 \%$ for the coping variables.

As shown in Figure 2, Structural Equation Modeling (SEM) generally confirmed the validaty of the research model. Self-efficacy affected coping by change (hypothesis H1 con- 
Psychological Resources and Coping Strategies (Research Article) - 12/14

Table 1

Correlations between variables.

\begin{tabular}{lccccccccc}
\hline & M & SD & $\mathbf{1}$ & $\mathbf{2}$ & $\mathbf{3}$ & $\mathbf{4}$ & $\mathbf{5}$ & $\mathbf{6}$ & $\mathbf{7}$ \\
\hline 1. Self-efficacy & 4.73 & 0.94 & - & & & & & \\
2. Optimism & 4.23 & 0.99 & $.41^{* *}$ & - & & & & \\
3. Hope & 4.50 & 0.81 & $.64^{* *}$ & $.56^{* *}$ & & & & \\
4. Resilience & 4.63 & 0.75 & $.58^{* *}$ & $.52^{* *}$ & $.56^{* *}$ & - & & \\
5. Change & 3.97 & 0.95 & $.21^{* *}$ & $.15^{* *}$ & $.18^{* *}$ & $.18^{* *}$ & - & \\
6. Acceptance & 4.03 & 0.82 & $.29^{* *}$ & $.37^{* *}$ & $.30^{* *}$ & $.39^{* *}$ & $.37^{* *}$ & - & \\
7. Withdrawal & 2.11 & 0.98 & $-.15^{* *}$ & $-.10^{*}$ & $-.15^{* *}$ & $-.12^{* *}$ & $.09^{*}$ & -.05 & - \\
\hline
\end{tabular}

Notes: $n=554 .{ }^{*} p<.05,{ }^{* *} p<.01$.

firmed); hope negatively affected coping by withdrawal (hypothesis $\mathrm{H} 3$ confirmed); and resilience affected coping by acceptance and coping by change (hypotheses $\mathrm{H} 4 \mathrm{~b}$, and $\mathrm{H} 4 \mathrm{a}$ confirmed).

Contrary to expectations, optimism did not have an effect on withdrawal (refuting hypothesis $\mathrm{H} 2$ ). The relationships between self-efficacy, hope, optimism, and resilience were expected in light of their relationship as multiple components of one structure, namely PsyCap. Moreover, there was a significant association between coping by acceptance and change, and between coping by withdrawal and change. There was no association between coping by acceptance and withdrawal.

\section{Discussion}

The research model assumed that the psychological capital capacities of self-efficacy, optimism, hope and resilience, would serve as a personal resource for coping, since coping evolves from resources and resources precede and influence coping (Lazarus \& Folkman, 1984). The basic premise was that the more psychological resources the individual has, the more he or she will choose coping by change and/or acceptance rather than withdrawal. These hypotheses were confirmed.

As hypothesized, the highest correlation between psychological resources and coping by change was found for self-efficacy. Individuals high in self-efficacy were disposed to view stress as a challenge to be overcome, and tend toward action and problem-focused coping. Nevertheless, all the psychological resources related significantly to coping by change. Consequently, the locus of control (in self-efficacy, optimism, and hope), viewing stress as a challenge (in self-efficacy and hope), and a strategic-pragmatic approach (in resilience) may lead to coping by changing the stressor.

Coping by acceptance was moderately correlated with each of the psychological resources, whereas the main contributors were resilience (as hypothesized) and optimism (not hypothesized). The ability to adapt, relearn, and be flexible, (resilience), as well as the expectation that good things will happen in the workplace (optimism), may lead to coping by acceptance. The relationship of withdrawal to each of the psychological resources was very low and negative. Thus, cre- ativity in finding new ways to cope in the workplace (hope), faith in one's ability to be successful at work (self-efficacy and hope), and perseverance (hope and resilience) may help individuals high in psychological resources avoid withdrawal.

As hypothesized, hope was negatively correlated with coping by withdrawal. Behavioral or psychological withdrawal from work is not consistent with achieving goals firmly but rather with helplessness. Optimism, contrary to the hypothesis, was found to have close to a zero correlation with withdrawal. The findings showed that optimism was mainly related to acceptance.

Although not predicted, all the psychological resources (self-efficacy, optimism, hope and resilience) correlated more strongly with coping by acceptance than with coping by change. In addition, resilience affected acceptance more than any of the resources affected coping. Consequently, psychological resources may prompt the individual to adapt to demands while framing the situation in a more positive way, rather than trying to change the stressors.

One way of accounting for these findings is to consider that the type of stress serves as a moderator of the relationship between psychological resources and coping. As suggested by (Eden 2011; quoted in Pines, 2011), the changeableness and continuity of stress can affect the direction of coping. In changeable situations with ongoing stress, direct-active coping is preferable, but when the stressor cannot be changed, direct-active action is not feasible. People can find temporary (by means of venting or diversion) or permanent (by means of self-change) relief, and adjust to the situation. The present study addressed chronic work stress as the object of coping. However, the interviewees may experience these stressors as fixed, such that the most efficient coping direction would be acceptance rather than change or withdrawal. If other stressors that are perceived as changeable had been examined, we might have found stronger relationship between psychological resources and change than between psychological resources and acceptance.

An alternative explanation is to consider that psychological capital, unlike human or social capital, primarily affects an individual's psychological abilities. The coping direction that 
requires the most personal psychological work is acceptance. Psychological capital deals with who you are now and who you will become in the future (Luthans et al., 2015). Hence, psychological capital identifies a transformation from one's actual self to one's possible self. Thus, acceptance may enable greater psychological growth than change, and much more than withdrawal when coping involves finding meaning that through an examination of values and goals. It is therefore possible that the relationship of psychological capital resources with acceptance is more powerful its relationship with other coping directions for various types of stress. This should be examined in future research.

\subsubsection{Limitations and suggestions for future research}

The present study has a number of limitations. The first is a methodological limitation: the data were gathered by means of self-report questionnaires; therefore, a report bias is possible. "Hard" measures of coping could improve the research (for example, examining avoidance coping by counting absences, etc.). Another problem concerns the correlations between the research variables, which were filled out by the same subjects.

The second limitation is that the coping questionnaire contained few items, which could compromise its reliability. In addition, it was developed by the researchers, and the tool should be tested and validated in other studies.

The third limitation is that all the research variables were examined simultaneously. Information about changes to the variables over time (longitudinal research) was not collected. This information is important when addressing dynamic variables.

Psychological capital resources significantly affected the coping directions studied here. Future work should investigate how it affects the stages before coping; namely, the initial appraisal stage (whether a certain situation is challenging or threatening) and the secondary appraisal (what the individual's resources are). The relationship between coping at the time of the stress event (as in this study), proactive coping (involving the accumulation of resources that might be useful if a threat occurs), and Psychological resources should be examined. In addition, self-efficacy was the most highly correlated with coping by change. Future work should consider the relationship between coping with stress and self-efficacy. As far as we know this concept has yet to be investigated.

\section{Conclusion}

The relationship between various forms of coping (by change, acceptance, and withdrawal) and positive psychological resources (self-efficacy, hope, optimism, and resilience) was examined and found to be significant. The present study contributes to explorations of new relationships between coping and psychological capital, and shows that increased conceptual accuracy can distinguish between psychological capital capacities (especially hope and resilience) and measurements of coping.

\section{Acknowledgment}

The authors acknowledge the valuable contribution of the late Prof. Dov Elizur to this research. Elizur, who passed away in September 2015, was part of the supervising team of the first author's $\mathrm{PhD}$ dissertation. He was a very special person and very dear to both of us. He will be in our hearts forever.

\section{References}

Amiot, C. E., Terry, D. J., Jimmieson, N. L., \& Callan, V. J. (2006). A longitudinal investigation of coping processes during a merger: Implications for job satisfaction and organizational identification. Journal of Management, 32(4), 552-574. doi: 10.1177/0149206306287542

Avey, J. B., Luthans, F., \& Jensen, S. M. (2009). Psychological capital: A positive resource for combating employee stress and turnover. Human Resource Management, 48(5), 677-693. doi: 10.1002/hrm.20294

Avey, J. B., Reichard, R. J., Luthans, F., \& Mhatre, K. H. (2011). Meta-analysis of the impact of positive psychological capital on employee attitudes, behaviors, and performance. Human Resource Development Quarterly, 22(2), 127-152. doi: 10.1002/hrdq.20070

Aybas, M., \& Acar, A. C. (2017). The effect of hrm practices on employees' work engagement and the mediating and moderating role of positive psychological capital. International Review of Management and Marketing, 7(1), 363-372. Retrieved from https: / / search.proquest.com/ docview/1865226749?accountid=28194

Carver, C. S. (1998). Resilience and thriving: Issues, models, and linkages. journal of social issues. Journal of Social Issues, 54(2), 245-266. doi: 10.1111/j.1540-4560.1998 .tb01217.x

Carver, C. S., \& Connor-Smith, J. (2010). Personality and coping. Annual Review of Psychology, 61, 679-704. doi: 10.1146/annurev.psych.093008.100352

Dewe, P. J., O’Driscoll, M. P., \& Cooper, C. L. (2010). Chichester, uk. In (chap. Coping with work stress: A review and critique (chapter 2)). Wiley-Blackwell. doi: 10.1002/9780470711712

Elizur, D. (1984). Facet of work values: A structural analysis of work outcomes. Journal of Applied Psychology, 69(3), 379-390. doi: 10.1037/0021-9010.69.3.379

Epstein-Mathias, S. (2003). Meta-analyses of coping processes (Unpublished doctoral dissertation). Bar- Ilan University.

Folkman, S. (1984). Personal control and stress and coping processes: A theoretical analysis. Journal of Personality and Social Psychology, 46(4). doi: 10.1037/ 0022-3514.46.4.839

Folkman, S., \& Moskowitz, J. (2007, 1). Positive affect and meaning-focused coping during significant psychological stress. In The scope of social psychology: Theory and applications (pp. 193-208). New York, 
NY: Psychology Press Taylor \& Francis Group. doi: $10.4324 / 9780203965245$

Guttman, L. (1946). The test-retest reliability of qualitative data. Psychometrica, 11(2). doi: 10.1007/BF02288925

Hobfoll, S. E. (1989). Conservation of resources: A new attempt at conceptualizing stress. American Psychologist, 44(3), 513-524. doi: 10.1037/0003-066X.44.3.513

Hobfoll, S. E. (2011). The oxford handbook of stress, health, and coping. In S. Folkman (Ed.), (p. 127147). Oxford University Press.

Holahan, C., Moos, R., \& Schaefer, J. (1996). Handbook of coping: Theory, research, applications. In M. Zeidner \& N. Endler (Eds.), (p. 24-43). New York, NY: John Wiley \& Sons, Inc.

Jöreskog, K. G., \& Sörbom, D. (1989). Lisrel 7: A guide to the program and applications (2nd ed.). Chicago, IL: SPSS Inc.

Korner, I. J. (1970). Hope as a method of coping. Journal of Consulting \& Clinical Psychology, 34(2). doi: 10.1037/ h0029004

Krasikova, D. V., Lester, P. B., \& Harms, P. D. (2015). Effects of psychological capital on mental health and substance abuse. Journal of Leadership \& Organizational Studies, 22(23), 134-139. Retrieved from https: / / search.proquest. com/ docview/1695772834?accountid=28194

Lazarus, R. S. (1999). Stress and emotion: A new synthesis. New Yor, NY: Springer. doi: 10.1046/j.1365-2850 .1999.00227-9.x

Lazarus, R. S., \& Cohen-Charash, Y. (2001). Emotions at work: Theory, research and applications for management. In R. L. Payne \& C. R. Cooper (Eds.), (p. 45-81). Chicherter, UK: John Wiley \& Sons, Ltd.

Lazarus, R. S., \& Folkman, S. (1984). Stress, appraisal, and coping. New York, NY: Springer.

Luthans, F., Vogelgesang, G. R., \& Lester, P. B. (2006). Developing the psychological capital of resilience. $\mathrm{Hu}$ man Resource Development Review, 5(1), 25-44. doi: $10.1177 / 1534484305285335$

Luthans, F., \& Youssef-Morgan, C. M. (2017). Psychological capital: An evidence-based positive approach. Annual Review of Organizational Psychology and Organizational Behavior, 4(1). doi: 10.1146/annurev-orgpsych -032516-113324

Luthans, F., Youssef-Morgan, C. M., \& Avolio, B. J. (2015). Psychological capital and beyond. New York, NY: Oxford, University Press.

Masten, A. S., \& Wright, M. O. D. (2010). Handbook of adult resilience. In J. W. Reich, A. J. Zautra, \& J. S. Hall (Eds.), (p. 213-238). New York, NY: The Guilford Press.

McDonald, R. P., \& Ho, M. R. (2002). Principles and practice in reporting structural equation analyses. Psychological Methods, 7(1), 64-82. doi: 10.1037/1082-989X.7.1.64

Newman, A., Ucbasaran, D., Zhu, F., \& Hirst, G. (2014).
Psychological capital: A review and synthesis. Journal of Organizational Behavior, 35(1), 120-138. doi: 10 .1002/job.1916

Pal, S., \& Bhardwaj, R. (2016). Personality, stress and coping resources among working women. Indian Journal of Health and Wellbeing, 7(9), 877-883. Retrieved from https: / / search.proquest.com/ docview/1837539778?accountid=28194

Pines, A. (2011). Burnout at work: Causes, results and coping strategies. Ben Shemen, IL: Modan Publishing.

Rabenu, E., Elizur, D., \& Yaniv, E. (2015). Facet theory: Searching for structure in complex social, cultural \& psychological phenomena. In A. Roazzi, B. Souza, \& W. Bilsky (Eds.), (p. 167-182). Recife, Brazil: Universitária/UFPE. Retrieved from https:// mega.nz/\#21ekRlFb6C21eIWKqRSxz _XbFLCq2XprNiSIA0QdI382MLIEVPZ-I 4 C doi: 10.17879/87219503184

Rabenu, E., Yaniv, E., \& Elizur, D. (2016). The relationship between psychological capital, coping with stress, wellbeing and performance. Current Psychology, 1(13). doi: 10.1007/s12144-016-9477-4

Seligman, M. E. P. (1998). Learned optimism (2nd ed.). New York, NY: Pocket Books (Simon and Schuster).

Skinner, E. A., Edge, K., Altman, J., \& Sherwood, H. (2003). Searching for the structure of coping: A review and critique of category systems for classifying ways of coping. Psychological Bulletin, 129(2), 216-269. doi: 10.1037/0033-2909.129.2.216

Smith, B. W., Tooley, E. M., Christopher, P. J., \& Kay, V. S. (2010). Resilience as the ability to bounce back from stress: A neglected personal resource? The Journal of Positive Psychology, 5(3), 166-176. doi: 10.1080/ 17439760.2010 .482186

Snyder, C. R. (2002). Hope theory: Rainbows in the mind. Psychological Inquiry, , 13(4), 249-275.

Snyder, C. R., Rand, K. L., \& Sigmon, D. (2002). Handbook of positive psychology. In C. Snyder \& S. Lopez (Eds.), (p. 257-276). Oxford, UK: Oxford University Press Inc.

Wang, X., Liu, L., Zou, F., Hao, J., \& Wu, H. (2017). Associations of occupational stressors, perceived organizational support, and psychological capital with work engagement among chinese female nurses. BioMed Research International.

Westman, M. (2004). Strategies for coping with business trips: A qualitative exploratory study. International Journal of Stress Management, 11(2), 167-176. doi: 10.1037/1072-5245.11.2.167 